\title{
HUGE SPORADIC AND COMPLEX CARDIAC RHABDOMYOMA WITH HYPOPLASTIC LEFT VENTRICLE AND LEFT LUNG
}

\author{
Türkan Tansel ${ }^{1}$, İbrahim Demir ${ }^{2}$, Nilgün Yazıksız ${ }^{1}$, Ümrah Aydoğan ${ }^{1}$, İbrahim Kalelioğlu ${ }^{1}$, \\ Recep Has ${ }^{1}$, and Emine Ylmazbayhan ${ }^{1}$ \\ ${ }^{1}$ Istanbul University Istanbul Faculty of Medicine \\ ${ }^{2}$ Istanbul University
}

February 14, 2021

\begin{abstract}
Cardiac rhabdomyomas are the most common fetal cardiac tumors and can be diagnosed antenatally and postnatally by echocardiography. They are usually asymptomatic and spontaneously regress within the first three years of life and often associated with tuberous sclerosis (TS). The prognosis of patients with rhabdomyomas is mostly determined by the size and location of the lesion. Rhabdomyomas may cause hemodynamic disturbances or arrhythmias due to obstructing the inflow or ventricular outflow tracts or alter valve function, leading to poor prognosis. Although it may regress spontaneously, surgical excision is usually curative, especially in sporadic and single tumors. We report an unique case of antenatally diagnosed as a huge cardiac rhabdomyoma accompanied by hypoplastic left lung and left ventricle, mimicking significant obstruction of the left ventricular and left atrial chamber. The patient underwent urgent surgery, because of severe hemodynamic compromise on the first day of life due to signs of severe obstruction of the left ventricle and left atrium. The large, lobulated epicardial cardiac rhabdomyoma located anterolateral and inferior aspect of the heart; involved the whole left ventricle through the left atrium excised.
\end{abstract}

\section{INTRODUCTION}

Cardiac rhabdomyomas are benign, the most common fetal cardiac tumors. They are usually associated with tuberous sclerosis (TS) with the incidence reported as high as $80 \%$ but may be sporadic (1-2). Cardiac rhabdomyomas are frequently diagnosed by means of fetal echocardiography during the prenatal period or during the first year of life. In most cases, no treatment is required and these lesions regress spontaneously (2). In rare instances with significant hemodynamic compromise, surgical resection has been the only option.

\section{CASE REPORT}

The patient was a male newborn and his prenatal echocardiographic examination in antenatal $27^{\text {th }}$ week revealed huge hypoechogenic mass involving the left ventricular free wall and left atrium with the largest diameter of $5 \mathrm{~cm}$. The left ventricular chamber was quite small, with no other intracardiac pathology of the fetus. There was a systolic murmur in the aortic area on postnatal examination. Heart sounds were deeply heard. The chest roentgenogram revealed a marked enlargement of the cardiac shadow. Postnatally, echocardiography showed a huge tumoral mass of the heart consisting anterolateral, lateral, apical and posterior part of the left ventricle, the mass involved also the left atrial wall. The right ventricle, right atrium, aorta, and pulmonary artery were normal. The pericard was presented free. The left ventricle was small, and volume was decreased. Clinical examinations results and family records have any evidence of tuberous sclerosis. 
The patient, who developed cardiorespiratory distress immediately after birth and symptoms of low cardiac output with a heart rate of below 100 beats per minute, blood pressure of below 40/25 $\mathrm{mmHg}$ and anuria, had endotracheal intubation, mechanical ventilation and inotropic support.

Macroscopically, a large, solid and white epicardial mass was observed which was located on the anterolateral and inferior wall of the heart involving the apical part (Fig 1a). The left lung was quite hypoplastic. Operation performed under partial cardiopulmonary bypass and moderate hypothermia, considering that the mass may have myocardial involvement. A biopsy from the white, solid and well-circumscribed tumor was performed for an intraoperative examination. The remaining lobulated mass was dissected from the epicardium, three separate solid masses attached to each other were detected and excised (Fig 1b). The left anterior descending coronary artery extrinsically compressed by tumor dissected carefully without damage. Left ventricular free wall stayed deplaced to the interventricular septum after total resection of masses. Sternum could not be closed due to cardiac edema and left the patient open chest.

The histopathological examination revealed several vacuolated eosinophilic cells with radial cytoplasmic extensions, known also as "spider cells" (Fig 2a). Anti-desmin immunopositivity leads us to diagnose the case as a cardiac rhabdomyoma with the presence of typical histopathological features (Fig 2b, Fig 3).

Left ventricular ejection fraction was measured as $30 \%$ after operation. Left ventricular volume was same as before operation. The patient died on the first postoperative day due to low cardiac output despite inotropic support.

\section{DISCUSSION}

Rhabdomyomas are the most common fetal cardiac tumor and usually associated with tuberous sclerosis but may be sporadic (1-2). Rhabdomyomas are frequently diagnosed by means of fetal echocardiography during the prenatal period. The prognosis of patients with rhabdomyomas is dependent on the number, size and location of the lesions as well as the presence or absence of associated anomalies (3-4). Tumors larger than $20 \mathrm{~mm}$ in diameter are more likely to cause hemodynamic disturbances or arrhythmias, which are associated with an increased risk of death (5). Associated congenital heart defects; hypoplastic left heart, tetralogy of Fallot and endocardial fibroelastosis have been reported (5-7). Extracardiac anomalies such as cleft palate, polycystic kidney and coexistence with chromosomal anomalies were also detected (5).

As a histological point of view, glycogen storage disease, histiocytoid cardiomyopathy and granular cell tumor are the main differential diagnosis of cardiac rhabdomyoma. The formation of distinct tumor nodules, the absence of epicardial surface involvement alone and the presence of radial cytoplasmic extensions in vacuolated cells (known also as spider cells) are the main morphological clues for diagnosing cardiac rhabdomyoma. Furthermore, the strong relationship with tuberous sclerosis manifesting with intracranial hamartoma, facial angiofibroma, linear epidermal nevi, renal angiomyolipoma and other hamartoma types should be kept in mind in patients diagnosed as cardiac rhabdomyoma.

Most patients can be managed conservatively, because they typically regress spontaneously with no hemodynamic effect (8). More recently, medical treatment with mammalian target of rapamycin (mTOR) inhibitors such as everolimus and sirolimus which act on a protein kinase that regulates cell growth, proliferation, protein synthesis, and transcription has been increasingly used with rapid regression of rhabdomyomas (9-10).

Rhabdomyomas that obstruct the inflow or ventricular outflow tracts or that alter valve function and lead to regurgitation also carry a poor prognosis and some patients need immediate surgical intervention in the early postnatal period $(1,8)$. Patients with large rhabdomyomas which are significantly associated with poor outcome, should be aware of the nature of their particular tumors and the type of surgical procedures available for treatment.

\section{REFERENCES}

1. Freedom RM, Lee KJ, MacDonald C, Taylor G. selected aspects of cardiac tumors in infancy and childhood. Pediatr Cardiol 2000; 21:299-32. Hinton RB, Prakash A, Romp RL, Krueger DA, Knilans TK. 
Cardiovascular manifestations of tuberous sclerosis complex and summary of the revised diagnostic criteria and surveillance and management recommendations from the international tuberous sclerosis consensus group. J Am Heart Assoc 2014; 3:1-11.

3. Isaacs H. Fetal and neonatal cardiac tumors. Pediatr Cardiol 2004; 25:252-73.

4. Degueldre SC, Chockalingam P, Mivelaz Y, Di Bernardo S, Pfammatter JP, Barrea C, et al. Consideration for prenatal counselling of patients with cardiac rhabdomyomas based on their cardiac and neurologic outcomes. Cardiol Young 2010;20:18-24.

5. Chao AS, Chao A, Wang TH, Chang YC, Chang YL, Hsieh CC, Lien R, Su WJ. Outcome of antenatally diagnosed cardiac rhabdomyoma: case series and meta-analysis. Ultrasound Obstet Gynecol 2008;31(3):289$95)$.

6. Holley DG, Martin GR, Brenner JI, Fyfe DA, Huhta JC, Kleinman CS, Ritter SB, Silverman NH. Diagnosis and management of fetal cardiac tumors: a multicentric experience and review of published reports. J Am Coll Cardiol 1995;26:516-520.

7. Watanabe T, Hojo Y, Kozaki T, Nagashima M, Ando M. Hypoplastic left heart syndrome with rhabdomyoma of the left ventricle. Pediatr Cardiol 1991;12:121-122.

8.Bader RS, Chitayat D, Kelly E, et al. Fetal rhabdomyoma: prenatal diagnosis, clinical outcome, and incidence of associated tuberous sclerosis complex. J Pediatr 2003;143;620-624.

9.Weiland MD, Bonello K, Hill KD. Rapid regression of large cardiac rhabdomyomas in neonates after sirolimus therapy. Cardiol Young 2018;28:485-489.

10. Chang JS, Chiou PY, Yao SH, Chou IC, Lin CY. regression of neonatal rhabdomyoma in two months through low-dose everolimus therapy: a report of three cases. Pediatr Cardiol. 2017;38:1478-1488.

Fig 1a, 1b: Epicardial mass that located on the anterolateral and inferior wall of the heart involving the apical part (1a), excised three separate solid masses attached to each other (1b).

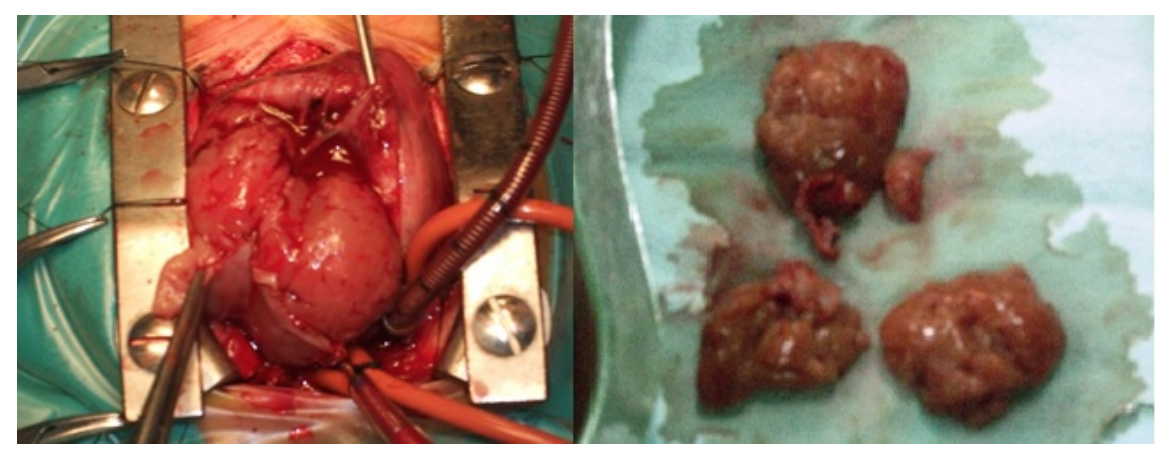




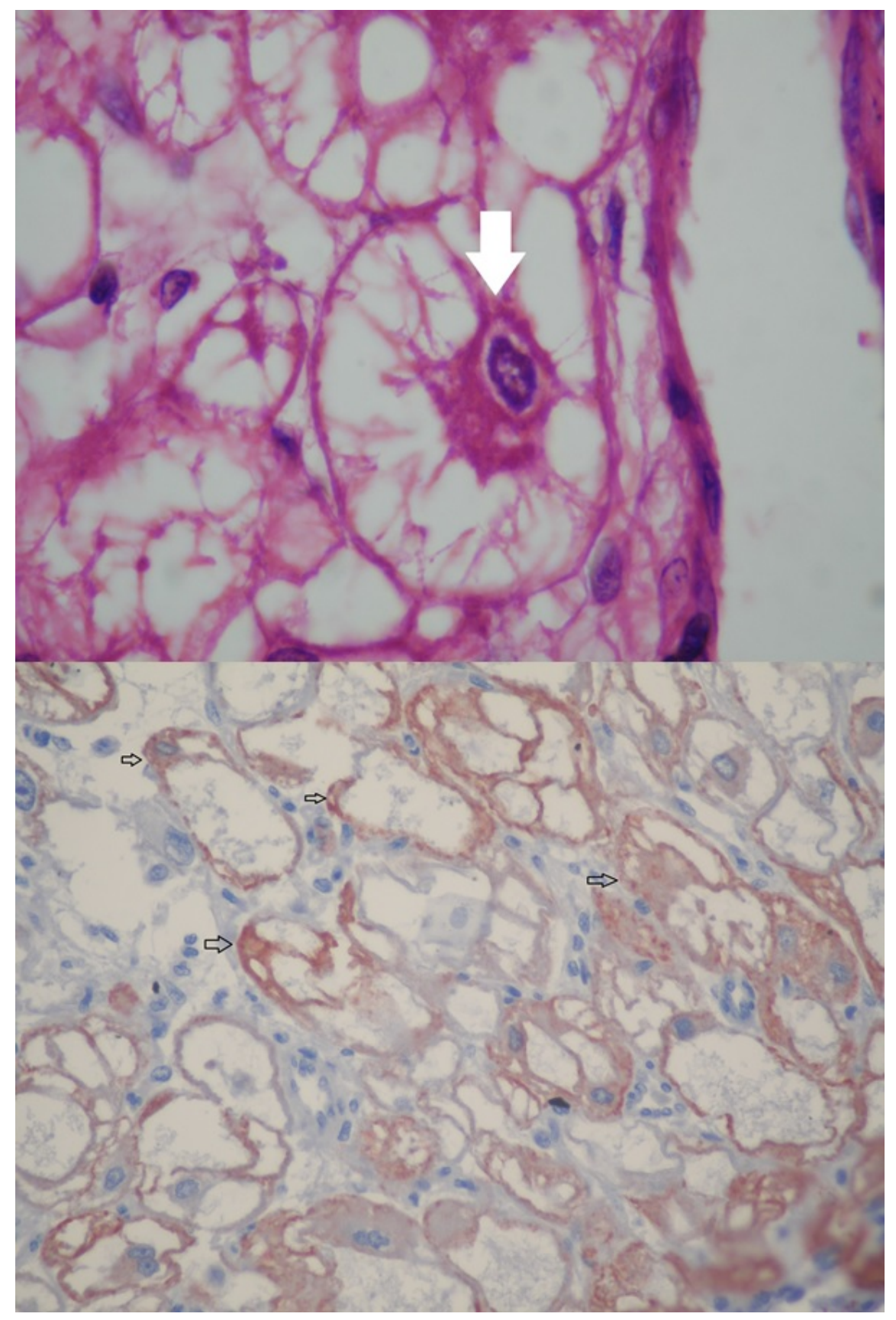

Fig 2a, 2b: Radial cytoplasmic extensions in vacuolated cells known also as 'spider cells' seen in histological material (marked with white arrow) (2a), Anti-desmin staining image on histological material (some of them marked with arrows) (2b).

Fig 3: The histopathological examination of mass. 

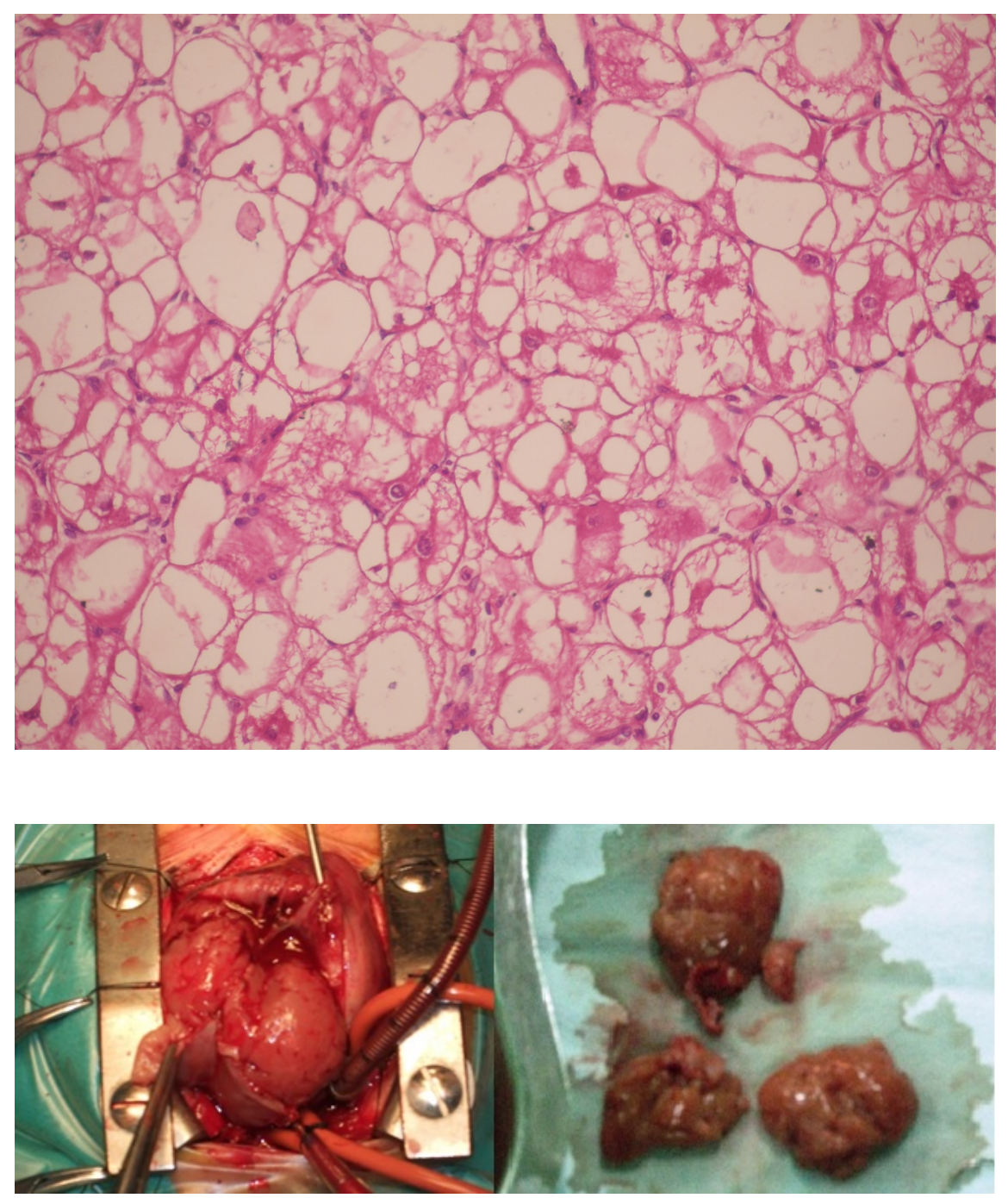


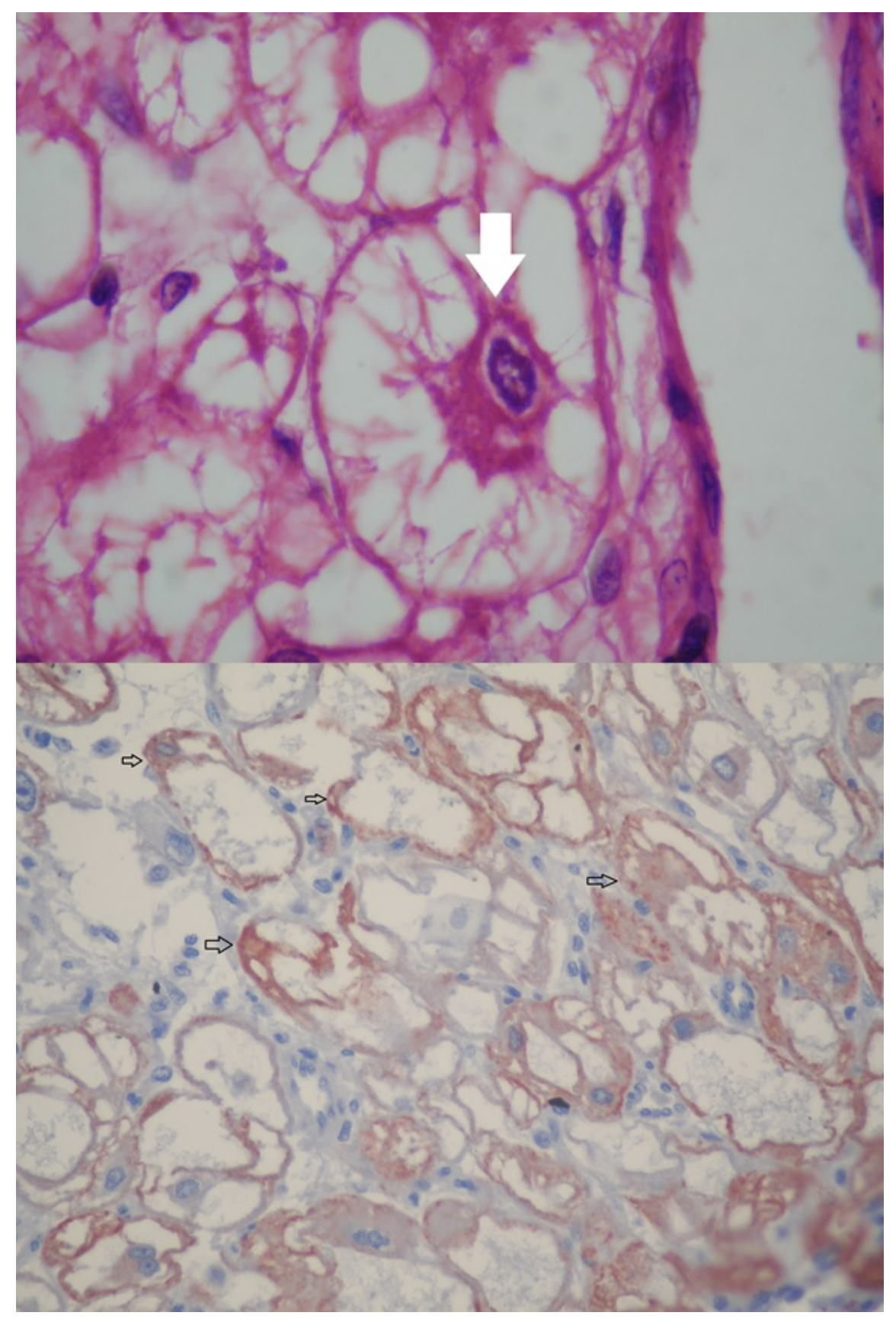




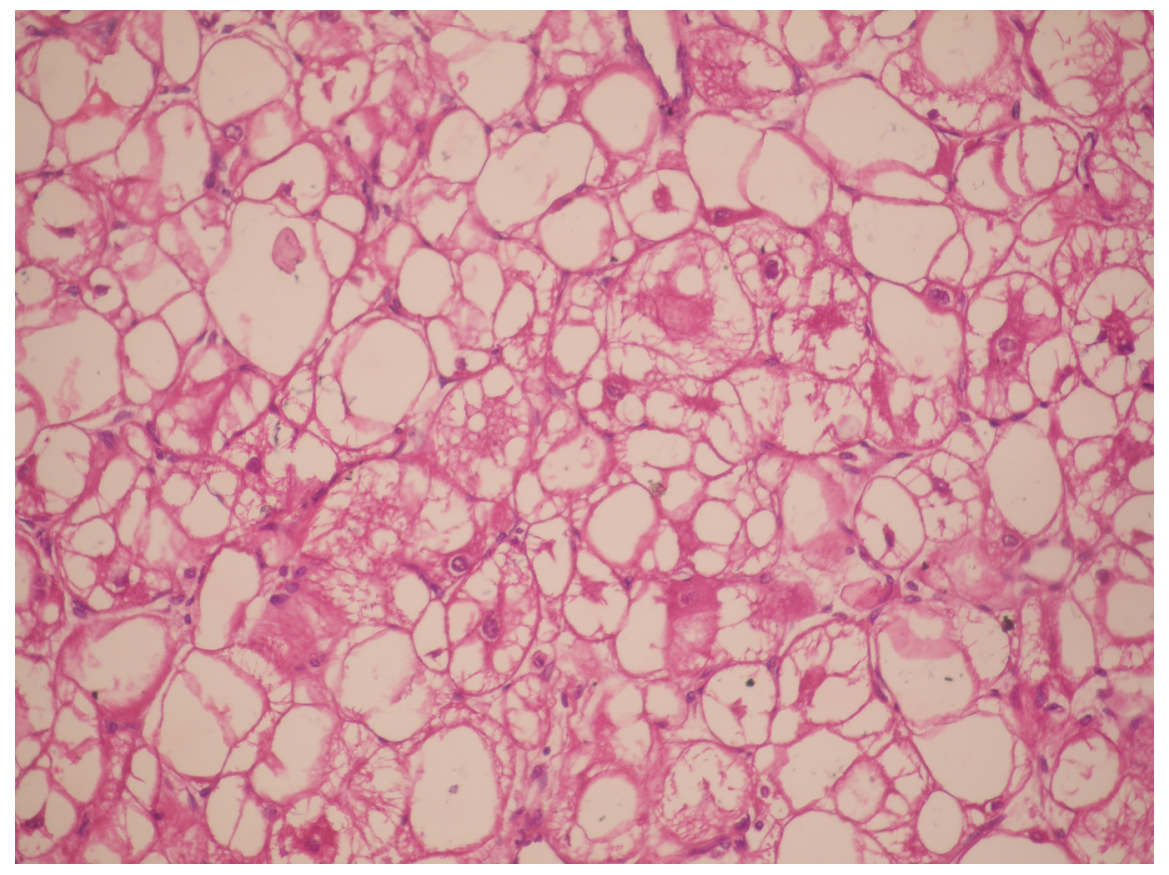

